\title{
Avaliação do desempenho do trabalhador como forma peculiar de prescrição do trabalho: uma análise do PMAQ-AB
}

Employee performance appraisal as a peculiar way of prescribing work: an analysis of $P M A Q-A B$

Paulo Navarro de Moraes ${ }^{1}$, Aparecida Mari Iguti²

'Mestrando em Saúde Coletiva no Departamento de Saúde Coletiva da Universidade Estadual de Campinas (UNICAMP) - Campinas (SP), Brasil. Professor da Faculdade de Medicina da Pontifícia Universidade Católica (PUC)

- Campinas (SP), Brasil.

paulonm@yahoo.com.br

${ }^{2}$ Doutorado em Anthropologie Et Ecologie Humaine pela Université Paris Descartes (PARIS 5) - Paris, França. Professora Associada do Departamento de Saúde Coletiva da Faculdades de Ciências Médicas da Universidade Estadual de Campinas (FCM/UNICAMP) Campinas (SP), Brasil. iguti@fcm.unicamp.
RESUMO: Este artigo descreve a avaliação do desempenho do trabalhador como um instrumento de gestão do trabalho caracterizado por inverter a clássica prescrição do trabaIho e tem como objetivo evidenciar a utilização deste instrumento na política pública de saúde, por meio da análise de conteúdo do Programa Nacional de Melhoria do Acesso e da Qualidade da Atenção Básica (PMAQ-AB). Os resultados são apresentados e discutidos em três grupos de categorias de análise relativos aos parâmetros, ao modo de condução e ao sistema de recompensa. Conclui-se que o PMAQ-AB constitui instrumento de gestão afeito às novas políticas de recursos humanos, sendo forma peculiar de prescrição do trabalho em saúde.

PALAVRAS-CHAVE: Avaliação de desempenho; administração de recursos humanos; saúde pública; atenção básica à saúde.

\begin{abstract}
This paper describes the employee performance appraisal as a work management tool characterized by reversing the classical 'prescription of work' and aims to show the use of this tool in public health policy, analyzing the content of the National Program for the Improvement of Access and Quality of Primary Care (PMAQ-AB). The results are presented and discussed in three groups of analysis categories, (1) the parameters, (2) the ways to conduct the assessment processes and (3) the reward system. We have concluded that the PMAQ-AB has similar characteristics of new personnel management adopted by private enterprises but as a peculiar way of 'prescribed work' in health care system.
\end{abstract}

KEYWORDS: Employee performance appraisal; Personnel management; Public health; Primary health care. 


\section{Introdução}

No campo da ergonomia, destaca-se a tese de que há uma diferença entre o que é chamado de trabalho prescrito e o trabalho real. Para Daniellou et al. (1989, p. 7), as empresas 'definem, previamente, uma produção, um trabalho, os meios para realizá-lo: estes são determinados a partir de regras, de normas e de avaliaçóes empíricas. São elementos previstos e, portanto, teóricos'. O trabalho prescrito é definido como

\section{[...] a maneira como o trabalho deve ser exe-} cutado: o modo de utilizar as ferramentas e as máquinas, o tempo concedido para cada operação, os modos operatórios e as regras a respeitar. Porém, 'este trabalho prescrito nunca corresponde exatamente ao trabalho real', isto é, o que é executado pelo trabalhador (DANIELLOU et al., 1989, p. 7). (Grifo nosso).

Brito (2009) observa que a percepção do fato de que o trabalho real não corresponde fielmente ao trabalho prescrito ocorreu, inicialmente, no contexto da análise de um trabalho organizado de maneira tayloris$t a$, que tem como uma de suas características marcantes a separação entre quem planeja ou prescreve o trabalho e quem o executa ou realiza.

Antunes (1995) considera que o chamado taylorismo-fordismo foi a forma predominante de organização do trabalho, especialmente do trabalho industrial, ao longo do século XX. Contudo, principalmente a partir da crise do capitalismo nos anos 1970, o modelo de produção em série e de massa, característico do fordismo, é substituído "por novos padróes de busca de produtividade, por novas formas de adequação da produção à lógica de mercado" (ANTUNES, 1995, p. 16).

Essas novas estratégias de gerenciamento recebem as mais diversas denominaçóes: 'gerenciamento estratégico participativo', 'gerenciamento de terceiro tipo', 'pós-fordismo', 'gerenciamento da qualidade total', entre outras. Para se referir a elas de uma maneira conjunta, Lima (1996, p. 23) vai utilizar a expressão Novas Políticas de Recursos Humanos (NPRH), denominação que passa a ser adotada com este sentido.
Autores como Lima (1996) e Campos (2007) questionam a 'novidade' dessas políticas. Lima considera que há um aproveitamento da formulaçấo da chamada Escola das Relaçóes Humanas e afirma que "a maior novidade que este 'novo' modelo gerencial apresenta não se encontra nos seus fundamentos, mas na abrangência de sua aplicação" (LIMA, 1996, p. 19). Já Campos considera que, em essência, o taylorismo não foi superado:

\section{[...] a marca central da organização moderna ou pós-moderna continua sendo o autoritarismo. Um autoritarismo, às vezes, revestido com palavras doces - parceria, integração, desenvolvimento de RH, flexibilização -, mas enganosas. Além de integrar-se ao espirito da firma, espera-se que os empregados o façam com um entusiasmo expressivo, quase histérico (CAMPOS, 2007, p. 23).}

A adoção das NPRH ocorre em um cenário de afirmação da ideologia neoliberal, principal resposta do capitalismo à crise iniciada nos anos 1970. Foucault aponta para uma definição do neoliberalismo sob três pontos de vista: sob o primeiro, econômico, é "a reativação de velhas teorias econômicas"; sob o segundo, sociológico, é a "instauração, na sociedade, de relações estritamente mercantis"; e sob o terceiro, político, é uma "cobertura para uma intervenção generalizada e administrativa do Estado" (FOUCAULT, 2008, p. 179). No mesmo sentido, Mészáros (2011, p. 153) afirma que, a despeito de toda a 'mitologia neoliberal' em sentido contrário, "o papel intervencionista do Estado nunca foi tão grande quanto no nosso tempo". $\mathrm{Na}$ alegoria de Bourdieu (1998) - de que o Estado possui uma "mão direita”, que representa e opera os interesses do Capital, e uma "mão esquerda", que representa e opera as políticas sociais e os interesses da classe trabalhadora - o Estado neoliberal torna-se definitivamente destro.

No Brasil, na contramáo da Constituição de 1988 - que ficou conhecida como a Constituição Cidadã por consagrar uma série de direitos típicos dos estados de bem-estar social, entre os quais o direito universal e integral à saúde -, o processo político conduziu à 
ascensão de Fernando Collor como primeiro presidente eleito após o período de ditadura militar e, com ele, tiveram início os processos de reforma do Estado dentro dos princípios neoliberais, seguindo a cartilha do Consenso de Washington (BATISTA, 1994).

Iniciado com Collor, este processo de reforma do Estado se aprofunda no governo Fernando Henrique Cardoso, quando a mesma se torna política de governo com status de Ministério - o Ministério da Administração Federal e Reforma do Estado (MARE). Para além da proposta de privatização da economia, a reforma do Estado brasileiro previa a incorporação de elementos típicos das NPRH na gestão dos serviços públicos, visando a uma transição da chamada administração burocrática para a administração gerencial. Nas palavras do então titular do MARE, Bresser Pereira:

\section{a Reforma do Aparelho do Estado voltada para} a gestão e busca de resultados, inclusive com indicadores, metas e avaliação de desempenho', é um processo de mudanças da instrumentalidade da ação do Estado, dos meios da governança, no manejo ou gerenciamento de seus recursos econômicos e sociais, na busca da eficiência (BRESSER PEREIRA apud CARINHATO, 2008 p. 42). (Grifos nossos).

Citada textualmente por Bresser Pereira, a Avaliação do Desempenho do Trabalhador constitui importante instrumento de gestão dentro das NPRH, justamente por sua característica de inverter a lógica taylorista da prescriçáo do trabalho: não mais se prioriza a determinação, a priori, do rol de atividades a serem desempenhadas, mas se determina o resultado que se espera do trabalho. Gera-se, portanto, uma forma peculiar de prescrição do trabalho. Para Merhy (1997, p. 20), esses novos modos de gerir as organizaçóes têm a finalidade de "garantir a 'captura' do trabalho vivo em ato na produção, permitindo que os autogovernos tenham que ser 'coerentes' com a natureza do processo produtivo capitalista".

No registro das NPRH, encontramos um reconhecimento da impossibilidade de anular a autonomia dos trabalhadores, a partir do controle preciso dos tempos e movimentos do corpo, como pretendia o taylorismofordismo mais tradicional. Desta forma, a gestão passa a conceder uma autonomia outorgada (LIMA, 1996), em que o trabalhador goza de liberdade para criar e (re) inventar o trabalho, desde que o faça de modo coerente com o processo produtivo capitalista.

Ao invés de se determinar o modo de produção, determina-se o que se espera do trabalhador e o que se espera do produto, deixando ao trabalhador a responsabilidade do sucesso ou do fracasso da produção, que será devidamente avaliado de forma a premiar ou punir o trabalhador, conforme o seu desempenho individual. A concorrência gerada entre os trabalhadores, neste cenário de introjeção da lógica capitalista no interior do ambiente de trabalho, garantiria que o uso da autonomia se desse em benefício principal dos interesses do capital. Contendo tanto os parâmetros de qualidade da produção quanto a lógica de indução da concorrência, por meio de um sistema de recompensas a ela associado, a avaliação do desempenho do trabalhador constitui o principal instrumento objetivo de inversão da prescrição do trabalho.

A adoção da avaliação do desempenho do trabalhador como instrumento de gestão do trabalho no âmbito do serviço público, longe de ser uma história acabada e datada nos anos 1990, continua viva no Brasil. Em 2010, o Decreto Presidencial no 7.133 (BRASIL, 2010) regulamentou 'os critérios e procedimentos gerais a serem observados para a realização das avaliaçóes de desempenho individual e institucional e o pagamento das gratificaçóes de desempenho' previstos em diversas legislaçóes específicas de carreiras de Estado.

Em 2011, a Portaria no 1.654 do Ministério da Saúde (BRASIL, 2011) cria o Programa Nacional de Melhoria do Acesso e da Qualidade da Atenção Básica (PMAQ-AB). Alencar et al. (2012, p. 8) incluem o PMAQ-AB no campo da Gestão por Resultados, que utiliza o instrumento Avaliação do Desempenho do Trabalhador como estratégia para conseguir "garantir o acesso e a qualidade da atenção à saúde para toda a população brasileira”, o que seria, na visão das autoras, a missão do Sistema Único de Saúde.

Este artigo se motiva pela discussão da utilização, nos serviços públicos de Atenção Básica à Saúde, das 
Novas Políticas de Recursos Humanos características do setor privado contemporâneo, em particular, o instrumento Avaliação do Desempenho do Trabalhador e sua característica de inversão da prescrição clássica do trabalho. O objetivo é identificar, através da análise de conteúdo do discurso normativo dos documentos oficiais e públicos do PMAQ-AB, os possíveis elementos de aproximação entre o programa e as NPRH.

\section{Metodologia}

Utilizou-se metodologia inspirada na Análise de Conteúdo, proposta por Bardin (2011), para proceder à análise dos documentos oficiais e públicos relacionados ao PMAQ-AB. Os documentos selecionados foram os seguintes:

- a Portaria no 1.654, de 19 de julho de 2011, que institui, no âmbito do Sistema Único de Saúde, o Programa Nacional de Melhoria do Acesso e da Qualidade da Atenção Básica (PMAQ-AB) e o Incentivo Financeiro do PMAQ-AB, denominado Componente de Qualidade do Piso de Atenção Básica Variável - PAB Variável (BRASIL, 2011), atualizada pela Portaria no 535 , de 3 de abril de 2013 (BRASIL, 2013). No escopo de dispositivos infralegais disponibilizados, há uma série de portarias que versam sobre a atualização e a definição de valores do componente de qualidade das diversas versôes do PMAQ;

- os Documentos: Autoavaliação para a Melhoria do Acesso e da Qualidade da Atenção Básica: AMAQ (BRASIL, 2012a); Programa Nacional de Melhoria do Acesso e da Qualidade da Atenção Básica (PMAQ): manual instrutivo (BRASIL, 2012b); Instrumento de Avaliação Externa da Saúde Mais Perto de Você - Acesso e Qualidade: Programa Nacional de Melhoria do Acesso e da Qualidade da Atenção Básica (BRASIL, 2012c); e Documento Síntese para Avaliação Externa (BRASIL, 2012d).
Além disto, incluímos a apostila completa do Curso de Autoaprendizado - Programa Nacional de Melhoria do Acesso e da Qualidade na Atenção Básica (PMAQ-AB), realizada pelo Ministério da Saúde em parceria com a Organização Pan-Americana de Saúde, com o Observatório de Políticas de Segurança Alimentar e Nutrição e com a Universidade de Brasília (ALENCAR et al., 2012), e o artigo O Programa Nacional de Melhoria do Acesso e da Qualidade da Atenção Básica: Reflexóes sobre o seu desenho e processo de implantação (PINTO; SOUSA; FLORÊNCIO, 2012), publicado na Revista RECIIS pelo Diretor do Departamento de Atenção Básica (DAB), por seu Diretor Adjunto e pelo Coordenador-Geral de Acompanhamento e Avaliação da Atenção Básica.

Para proceder à análise, foi construído um conjunto de categorias de análise, seguindo a linha metodológica de Bardin. Para a autora, a categorização é um processo de tipo estruturalista, que comporta duas etapas: o inventário, onde o pesquisador busca isolar os elementos; e a classificação, onde o pesquisador busca repartir os elementos e, portanto, procura impor certa organização às mensagens (BARDIN, 2011).

Foi realizada uma definição prévia das categorias, pois, segundo Bardin, "este é o procedimento [...] aplicável no caso de a organização do material decorrer diretamente dos funcionamentos teóricos hipotéticos" (BARDIN, 2011, p. 149).

O conjunto de categorias de análise foi construído a partir de uma leitura dos dispositivos de controle implícitos inerentes às NPRH, assim descritos por Lima:

- A atenção dada ao cliente e a concentração sobre o exterior, consideradas como a 'via mais rigorosa da autodisciplina';

- A pressão exercida pelos pares, definida como o mais rigoroso dispositivo de controle;

- O tamanho reduzido das divisóes, que facilita sua gestão;

- A autonomia outorgada, considerada como produto da disciplina. $\mathrm{O}$ trabalhador tem a 
Quadro 1. Conjunto de categorias de análise

\begin{tabular}{|c|c|}
\hline GRUPO & CATEGORIAS \\
\hline Parâmetros & $\begin{array}{l}\text { Introjeção de missão e valores } \\
\text { Compromisso ético-político } \\
\text { Foco no exterior } \\
\text { Autonomia outorgada } \\
\text { Especialização flexível }\end{array}$ \\
\hline Modo de condução & $\begin{array}{l}\text { Arbítrio gerencial } \\
\text { Controle pelos pares }\end{array}$ \\
\hline Sistema de recompensas & $\begin{array}{l}\text { Motivação } \\
\text { Cobrança dos pares } \\
\text { Remuneração por desempenho }\end{array}$ \\
\hline
\end{tabular}

Fonte: Elaboração Própria

permissão de usufruir da sua liberdade de uma maneira que corresponda aos objetivos da empresa. Não podemos nos esquecer de que este modo de agir, mais permissivo, pode engajar mais fortemente a responsabilidade dos indivíduos;

- Os fundamentos éticos, como a valorização do trabalho, considerado como um dever em relação à comunidade;

- A individualização dos salários e dos assalariados ${ }^{1}$;

- A tentativa de criar o consenso e um ambiente homogêneo (valores, regras e princípios compartilhados);

- $\mathrm{O}$ autocontrole, que substitui a coerção;

- A conjugação da exigência e da precisão com a flexibilidade (LIMA, 1996, p. 39-40).

${ }^{1}$ Desta forma, segundo Lima, reduz-se a pressão da organização dos trabalhadores e da reivindicação coletiva, ao passo que valoriza uma competição intensa entre esses mesmos trabalhadores.
Foram consideradas, além destes dispositivos, as características essenciais de um processo avaliativo, os propósitos e o modo de condução (GUBA; LINCOLN, 2011). Quanto aos propósitos, foi possível identificar, com base na literatura estudada, dois principais, associados à Avaliação do Desempenho do Trabalhador: a manutenção de um coeficiente elevado de alienação do trabalho, que se dá a partir da definição dos parâmetros, e a instalação de uma concorrência entre os trabalhadores, que se dá a partir da introdução de um Sistema de Recompensas.

Assim, com base nestes referenciais, chegou-se a um total de dez categorias de análise, divididas em três grupos: Parâmetros, Modo de Condução e Sistema de Recompensas. O resultado desta construção encontra-se sintetizado no Quadro 1, abaixo.

\section{Análise do conteúdo dos documentos oficiais do PMAQ-ABw}

\section{QUANTO AOS PARÂMETROS}

O PMAQ-AB trabalha com um sofisticado escopo de parâmetros que, de maneira resumida, consiste dos indicadores de desempenho e de monitoramento, contratualizados com municípios e equipes na Fase 1, e uma 
gama de padrôes de qualidade, utilizados em parte no momento de autoavaliação e no todo, quando da Avaliação Externa (BRASIL, 2012b).

Em todos os casos, os parâmetros estão determinados nos documentos oficiais pesquisados e, portanto, os trabalhadores das equipes de atenção básica não possuem qualquer possibilidade de participar de sua formulação, o que reforça a alienação do trabalho e a Racionalidade Gerencial Hegemônica (CAMPOS, 2007).

Nos documentos pesquisados, há uma clara referência ao uso do PMAQ-AB no contexto de um modelo de gestão por resultados, em que a missão do Sistema Único de Saúde seria 'garantir o acesso e a qualidade da atenção à saúde para toda a população brasileira' (ALENCAR et al., 2012, p. 8). Trabalha-se, portanto, no PMAQ, com a perspectiva de introjeçáo de missáo e valores nos trabalhadores, valores estes que, segundo a interpretação feita do Manual Instrutivo do PMAQ$-\mathrm{AB}$, foram construídos na forma de indicadores e padrōes de qualidade, 'buscando sinergia entre o PMAQ e as prioridades pactuadas pelas três esferas de governo' (BRASIL, 2012b, p. 25).

No mesmo sentido, é possível perceber a exigência de um compromisso ético-político, presente, por exemplo, no trecho: "Estimular [...] a responsabilidade sanitária dos profissionais e gestores de saúde com a melhoria das condiçôes de saúde e satisfação dos usuários" ( BRASIL, 2012b, p. 8). A estratégia para este estímulo, como é da característica deste modelo de gestão, é a introdução de indicadores e padróes de qualidade que possam induzir este compromisso nos trabalhadores, uma vez que serão cobrados. Mais do que induzir "padrões de boas práticas” (BRASIL, 2012b, p. 8), busca-se aqui, também, trabalhar com a modulação do perfil profissional.

Para Pinto, Sousa e Florêncio (2012), a adesão e a contratualização individualizada por equipe tentou introduzir um dispositivo concreto de viabilização do reconhecimento intersubjetivo dos indivíduos, que devem se responsabilizar pelo conjunto de açóes capazes de promover a ampliação do acesso e da qualidade da atenção básica.

A expectativa de um 'reconhecimento intersubjetivo dos indivíduos', para que se responsabilizem pelo conjunto de açóes pensadas pelos formuladores do programa, também constitui evidência da tentativa de introjeção de missão e valores.

O foco no exterior é claramente identificado em várias passagens dos documentos oficiais analisados, a começar pela repetida referência à 'satisfação do usuário’ (BRASIL, 2011, 2012b, 2012c, 2012d). Aqui é possível construir uma analogia entre o usuário do SUS e o 'cliente' da empresa privada. A satisfaçáo da clientela é um dos elementos centrais do PMAQ-AB (PINTO; SOUSA; FLORÊNCIO, 2012).

Entretanto, o foco no exterior verificado nos parâmetros do PMAQ-AB transcende o componente 'satisfação da clientela', uma vez que boa parte dos padróes de qualidade remete a resultados (política de gestão por resultados) verificáveis externamente. Pelo instrumento de avaliação externa (BRASIL, 2012c), sempre que possível, é solicitada prova documental da realização do padrão de qualidade em questão.

O próprio momento avaliativo é denominado Avaliação Externa, uma vez que experts oriundos de instituiçôes de ensino e pesquisa vêm verificar, in loco, as evidências de que os resultados esperados foram efetivamente alcançados.

O componente autonomia outorgada também se encontra presente na análise dos documentos oficiais pesquisados. No Manual Instrutivo do PMAQ-AB, o termo autonomia aparece remetido às dimensóes de educação permanente e apoio institucional. No primeiro caso, reforça que é preciso, para a transformação do modelo de atenção, que, entre outras, os trabalhadores tenham "maior capacidade de análise, intervenção e autonomia para o estabelecimento de práticas transformadoras" (BRASIL, 2012b, p. 46). No segundo caso, encontra-se a referência de que o "apoio institucional na saúde deve buscar, portanto, a democracia institucional, a ampliaçấo dos graus de autonomia dos sujeitos, a defesa da vida e dos princípios e diretrizes do SUS" (BRASIL, 2012b, p. 47). No mesmo documento, encontra-se ainda a seguinte colocação:

a seleção dos elementos que comprovam adequação aos padróes de qualidade considera também soluçôes locais e inovaçôes que cumpram os objetivos vinculados ao padrão, principalmente 
os relacionados aos processos de trabalho, não se limitando à criatividade e proatividade das equipes e da gestão municipal (BRASIL, 2012b, p. 52).

Percebe-se, portanto, que há um claro estímulo para que as equipes de atenção básica produzam soluçóes inovadoras, para atingir tos resultados esperados pelos formuladores do programa, constituindo exemplo inequívoco da prática da autonomia outorgada.

Por fim, o componente de especializaçáo flexível também se encontra muito presente nos documentos analisados, em especial, no documento AMAQ (BRASIL, 2012a), que define os padróes de qualidade. Existe um padrão de qualidade específico que remete à questão da formação, tanto do ponto de vista da titulação dos profissionais quanto do ponto de vista de suas "habilidades e competências":

Os profissionais de nivel superior da equipe de atenção básica têm formação qualificada para atuarem na $A B$. Tais qualificaçöes contribuem para que desenvolvam açôes de saúde mais resolutivas no território, promovendo melhor desempenho técnico e profissional, novas competências e habilidades, bem como melhoria nos processos de trabalho, planejamentos e intervençôes da equipe. São exemplos de formação complementar: Especialização em Saúde da Família, Saúde Coletiva, Medicina Preventiva e Social, Residência em Medicina de Família e Comunidade, Especialização em Odontologia Preventiva e Social, Saúde Bucal Coletiva etc. (BRASIL, 2012a, p. 57).

Outro padrão de qualidade (abaixo) mostra, com ainda maior clareza, esta exigência de uma especialização flexível. Os dois padrôes estão presentes na subdimensão 'Perfil da Equipe':

Os profissionais da equipe utilizam suas habilidades, conhecimentos e competências (para além das atribuiçóes profissionais) em torno da ampliação da capacidade de equipe de produzir saúde de maneira compartilhada $e$ motivadora. Por exemplo: liderança e criatividade, capacidade de produzir inovaçôes e lidar com dissensos, mediação de conflitos, capacidade de escuta (BRASIL, 2012a, p. 58).

\section{QUANTO AO MODO DE CONDUÇÃO}

O PMAQ-AB constitui um instrumento de avaliação bastante complexo, com vários momentos. Entre estes, dois em especial configuram momentos avaliativos: o momento da autoavaliação (primeira dimensão da Fase 2) e o momento da Avaliação Externa (Fase 3).

Para o momento da autoavaliação, o PMAQ-AB permite um processo mais livre, embora tenha a recomendação/oferta da utilização da AMAQ (BRASIL, 2012a) como instrumento. Sua utilização não é, portanto, exigida, mas se mostra particularmente útil, na medida em que define parte dos padróes de qualidade que serão utilizados para a avaliação externa.

O momento de avaliação externa, por sua vez, pode ser considerado, efetivamente, $\mathrm{o}$ ato avaliativo propriamente dito. Dizemos isto porque a fase de autoavaliação é considerada neste momento, e pontua na classificação final em um sistema binário: foi feita ou não foi feita. Para que se pontue, neste caso, a equipe deve apresentar ao avaliador externo documento comprobatório desta realização (ata de reuniáo de equipe, por exemplo). Se puder comprovar que fez uma autoavaliação, a equipe recebe os pontos atribuíveis (10\% do total); se não houver esta comprovação, não recebe os pontos. Assim, para efeito do resultado da avaliação, pouco importa o produto da autoavaliação.

A avaliação externa é composta por quatro módulos, distintos pelo método de coleta de dados: no módulo 1, o avaliador irá observar as condiçôes de infraestrutura, materiais, insumos e medicamentos da Unidade Básica de Saúde; no módulo 2, caberá ao avaliador entrevistar o trabalhador designado pela equipe para esse momento - a este serão feitas perguntas sobre o processo de trabalho e sobre a organização do cuidado ao usuário, bem como the serão solicitados os documentos comprobatórios, conforme o padrão de qualidade em questão; no módulo 3, o avaliador entrevistará 
um usuário do serviço, buscando as informaçóes referentes à satisfação do mesmo; e o módulo 4 consiste da consulta online de questóes complementares aos módulos anteriores, que deverão ser respondidas pelos gestores ou pelos trabalhadores (a depender da atribuição) na plataforma eletrônica do programa.

Diante do exposto, percebe-se que, na Avaliação do Desempenho do Trabalhador prescrita pelo PMAQ$\mathrm{AB}$, há uma possibilidade menor de arbítrio gerencial. Talvez o momento em que isto possa acontecer não seja na condução da avaliação, mas na fase de adesão/contratualização. Entretanto, como afirmam Pinto, Sousa e Florêncio (2012), a necessidade de que a equipe também assine a adesão e contratualize os indicadores de desempenho e monitoramento constitui uma potencial defesa dos trabalhadores contra o arbítrio gerencial.

Tampouco se observa a pressão exercida pelos pares - controle dos pares - no ato de condução da avaliação, uma vez que a relação direta existente é entre o avaliador externo e um representante da equipe (Módulo 2 da avaliação externa).

\section{QUANTO AO SISTEMA DE RECOMPENSAS}

O caráter competitivo do PMAQ-AB fica explícito em seu modo de configuração do pagamento do componente de qualidade do $\mathrm{PAB}$, variável em função do desempenho obtido pelas equipes da atenção básica. Assim, utiliza-se a técnica estatística de agrupamento, para classificar as equipes da atenção básica pertencentes a um mesmo estrato em quatro categorias possíveis: muito acima da média; acima da média; na média; e abaixo da média ou insatisfatório.

Com as mudanças introduzidas pela Portaria 535/2013 (BRASIL, 2013), a categoria insatisfatório fica restrita às equipes de serviços/unidades que não cumprem os requisitos mínimos de permanência. As demais possibilidades de classificação referem-se à distância em relação à média, calculada por desvios-padrão, de forma que sempre haverá equipes classificadas nas três categorias, sendo impossível a hipotética situação de todas as equipes receberem $100 \%$ do componente de qualidade do PAB Variável (pois, para que se fique 'muito acima da média', é necessário que outras equipes estejam na média e abaixo dela). Se todas as equipes atingissem a nota máxima, estariam todas na média e, portanto, fariam jus a apenas 20\% do valor relativo ao referido componente. Este é o valor que é repassado às equipes quando da adesão, ou seja, um desempenho máximo de todas as equipes (situação ideal) não representaria nenhum investimento a mais nessas equipes.

O PMAQ-AB, a priori, não prevê um sistema de recompensas que atinja diretamente o trabalhador da equipe de Atenção básica. O componente de qualidade do PAB Variável é um recurso transferido diretamente do Fundo Nacional de Saúde para o Fundo Municipal de Saúde correspondente.

Embora nos documentos oficiais não haja previsão de remuneraçáo por desempenho, existem experiências, em alguns municípios, em que os recursos do componente de qualidade do PAB Variável são empregados, no todo ou em parte, em bonificação no rendimento dos trabalhadores. Segundo informação constante do sítio do DAB na internet, a implantaçâo do PMAQ-AB "é uma oportunidade de viabilizar ou instrumentalizar a adoção de mecanismos de remuneração por desempenho". Tal informação encontra consonância com o padrão de qualidade:

A gestão municipal remunera os trabalhadores
considerando também o desempenho das equi-
pes de atenção básica. Reconhece e valoriza o
processo de trabalho das equipes a partir de
critérios bem definidos, pactuando, por meio
de instrumentos de planejamento, contratu-
alização e avaliação de metas e resultados. A
gestão promove o apoio técnico e gerencial para
as equipes com desempenho insatisfatório e mo-
nitora e avalia os indicadores pactuados (BRA-
SIL, 2012a, p. 35).

Uma vez que se trata de um programa em nível nacional, não é de responsabilidade do Ministério da Saúde a contratação e remuneração direta de trabalhadores da Atenção Básica à Saúde. Esta é uma responsabilidade dos municípios, de acordo com a Política Nacional de Atenção Básica (BRASIL, 2012e). Assim, 
o mecanismo disponível é uma política de indução e estímulo, conforme se verifica nos trechos supracitados.

Se a remuneração por desempenho é apenas uma 'oportunidade' a ser viabilizada pelos municípios, há que se refletir sobre que mecanismos de motivaçáo sáo verificáveis para que os trabalhadores de municípios que não adotam a remuneração por desempenho vinculada aos recursos oriundos do PMAQ-AB possam se engajar no programa.

Boa parte dos municípios, se não revertem diretamente aos trabalhadores das suas equipes de atenção básica, pelo menos, parte do componente de qualidade do PAB Variável, o fazem indiretamente com investimentos que podem significar uma melhoria das condiçôes de trabalho.

Não se pode também descartar a potência das recompensas simbólicas. Para Lima (1996, p. 24), "a sua função é de sustentar positivamente o comportamento" e, portanto, tais recompensas têm uma importância especial para as empresas que as adotam. Podemos pressupor que haveria um efeito similar em sua adoção nos serviços públicos de Atenção Básica à Saúde.

A forma de concorrência estabelecida pelo PMAQ-AB não é individual, mas sim por equipes. Neste cenário, a pressão exercida pelos pares adquire as características de cobrança pelos pares, em que há uma cobrança mútua entre os trabalhadores, uma vez que o desempenho individual de um trabalhador pode comprometer o resultado final de toda a equipe.

Tomem-se, por exemplo, os indicadores previstos na fase de contratualização, dentro da área estratégica 'produção geral' (BRASIL, 2012b). Esta área comporta 12 indicadores, sendo que 4 deles são considerados indicadores de desempenho e, portanto, são utilizados no cálculo do resultado de certificação da equipe. Entre os doze indicadores, existem os que são relativos ao trabalho dos profissionais médico, enfermeiro e agente comunitário de saúde.

Entretanto, dentre os quatro indicadores de desempenho, todos são relativos ao trabalho do profissional médico: (1) média de consultas médicas por habitante; (2) proporção de consultas médicas para cuidado continuado/programado; (3) proporçáo de consultas médicas de demanda agendada; e (4) proporção de consultas médicas de demanda imediata.

Neste exemplo específico, todo o resultado da equipe nesta área estratégica depende do desempenho do profissional médico. Desta forma, toda a cobrança sobre o mau desempenho, por parte da equipe, será feita também sobre o profissional médico. Estima-se que este exemplo seja suficiente para demonstrar de que forma a cobrança pelos pares pode atuar dentro do PMAQ-AB.

\section{Considerações Finais}

O PMAQ tem sido uma das principais políticas do atual Ministério da Saúde voltadas para a atenção básica. Os resultados encontrados nesta pesquisa, considerando-se os referenciais teóricos utilizados, nos permitem concluir que o conteúdo dos documentos oficiais do programa aponta para um modelo de gestão baseado na Avaliação do Desempenho do Trabalhador, que apresenta grande aproximação com a inversão da prescrição do trabalho, peculiar às NPRH, no âmbito da Atenção Básica no Brasil. Campos, no prefácio do livro "Desafios da avaliação de programas e serviços de saúde", afirma que

a utilização da avaliação em políticas públicas, com a função de aproximá-las da lógica e da racionalidade do mercado, é uma escolha deliberada, iluminada por uma concepção de mundo, que vê na competição permanente entre os atores sociais, pessoas e organizaçôes, julgados segundo a competência e o mérito, uma forma de construir-se qualidade e eficiência (CAMPOS, 2011, p. 14).

Considera-se que esta 'concepção de mundo' de que nos fala Campos corresponde à visão neoliberal que, se deixou marcas profundas com o processo de privatização e reforma do Estado, também avançou extraordinariamente no campo da disputa ideológica, de forma a se tornar hegemônica em nossa sociedade atual.

Se esta pesquisa nos permite afirmar que os instrumentos de Avaliação do Desempenho do Trabalhador 
do PMAQ-AB situam-se no campo da gestão do trabalho definido por Lima como Novas Políticas de Recursos Humanos, ela não nos autoriza a generalizar tal conclusão para todos os processos de avaliação relacionados às políticas públicas e ao trabalho no âmbito do serviço público de saúde.

Afirma-se a necessidade de se ter serviços públicos de saúde com qualidade e eficiência, até como forma de se fortalecer e legitimar a 'mão esquerda' do Estado, retomando a alegoria de Bourdieu (1998). Entende-se, contudo, que esta qualidade e eficiência não serão efetivas ao desconsiderarem o papel protagonista dos trabalhadores da saúde, até porque o encontro entre estes e os usuários, que caracteriza o trabalho real em saúde ou o 'trabalho vivo em ato' (MERHY, 1997), considerando a predominância das tecnologias leves, se dá em um espaço protegido da interferência da gestáo.

Reconhecer, nos trabalhadores da saúde, sujeitos portadores de necessidades, interesses e desejos próprios (CAMPOS, 2007), e conceber modos democráticos de gestão em que estes fatores possam ser negociados, levando-se em conta, também, as necessidades, interesses e desejos dos usuários do SUS e dos governos, coproduzindo arranjos singulares, parece um caminho mais promissor para alcançar a qualidade e a eficiência, ampliando a capacidade de análise e intervenção dos sujeitos envolvidos (CAMPOS, 2007).

\section{Referências}

ALENCAR, B., PEREIRA, M. e RAMOS, N. Curso de Autoaprendizado - Programa Nacional de Melhoria do Acesso e da Qualidade na Atenção Básica (PMAQ-AB) - Apostila completa. Realização: Ministério da Saúde, Organização Pan-Americana da Saúde, Observatório de Políticas de Segurança Alimentar e Nutrição e Universidade de Brasília. Brasília, 2012 . Disponível em: <http://ecos-redenutri.bvs. br/tiki-download_file.php? fileld=149>. Acesso em: 09 out. 2013.

ANTUNES, R. Adeus ao trabalho? Ensaio sobre as metamorfoses e a centralidade do mundo do trabalho. Campinas, SP: UNICAMP, 1995.

BARDIN, L. Análise de conteúdo. Tradução Luis Alberto Reto e Augusto Pinheiro. São Paulo: Edições 70, 2011.

BATISTA, P. N. O consenso de Washington: a visão neoliberal dos problemas latino-americanos. 2004. Disponível em: <http:// www.fau.usp.br/cursos/graduacao/arq_urbanismo/disciplinas/ aup0270/4dossie/nogueira94/nog94-cons-washn.pdf>. Acesso em: 18 ago. 2013.

BOURDIEU, P. Contrafogos: táticas para enfrentar a invasão neoliberal. Tradução Lucy Magalhães. Rio de Janeiro: Zahar, 1998.

BRASIL. Ministério da Saúde. Gabinete do Ministro. Portaria n. 1.654 de 19 de julho de 2011 - Institui, no âmbito do Sistema Único de Saúde, o Programa Nacional de Melhoria do Acesso e da Qualidade da Atenção Básica (PMAQ-AB) e o Incentivo Financeiro do PMAQ-BA, denominado Componente de Qualidade do Piso de Atenção Básica Variável - PAB Variável . 2011a. Disponível em: <http://www.brasilsus.com.br/legislacoes/gm/108814-1654. html>. Acesso em: 19 set. 2012.

Ministério da Saúde. Gabinete do Ministro. Portaria n. 535, de 03 de abril de 2013 - Altera a Portaria no 1.654/GM/MS, de 19 de julho de 2011, que institui, no âmbito do Sistema Único de Saúde, o Programa Nacional de Melhoria do Acesso e da Qualidade da Atenção Básica (PMAQ-AB). . Disponível em: <http://bvsms. saude.gov.br/bvs/saudelegis/gm/2013/prt0535_03_04_2013. html>. Acesso em: 09 out. 2013.

Ministério da Saúde. Gabinete do Ministro. Portaria n. 866/GM/MS, de 3 de maio de 2012, que altera o prazo para solicitação da avaliação externa no Programa Nacional de Melhoria do Acesso e da Qualidade da Atenção Básica (PMAQ-AB). Disponível em: <http://bvsms.saude.gov.br/bvs/saudelegis/gm/2013/ prt0535_03_04_2013.html>. Acesso em: 09 out. 2013.

Ministério da Saúde. Secretaria de Atenção à Saúde. Departamento de Atenção Básica. Autoavaliação para a Melhoria do Acesso e da Qualidade da Atenção Básica: AMAQ. Brasília: Ministério da Saúde, 2012a. (Série B. Textos básicos de saúde)

Ministério da Saúde. Secretaria de Atenção à Saúde. Departamento de Atenção Básica. Programa Nacional de Melhoria do Acesso e da Qualidade da Atenção Básica (PMAQ: Manual Instrutivo). Brasília: Ministério da Saúde, 2012b. (Série A. Normas e manuais técnicos).

Ministério da Saúde. Secretaria de Atenção à Saúde. De- 
partamento de Atenção Básica. Instrumento de Avaliação Externa do Saúde Mais Perto de Você - Acesso e Qualidade: Programa Nacional de Melhoria do Acesso e da Qualidade da Atenção Básica. Brasília: Ministério da Saúde, 2012c. (Série A. Normas e manuais técnicos).

Ministério da Saúde. Secretaria de Atenção à Saúde. Departamento de Atenção Básica. Documento síntese para avaliação externa - Programa Nacional de Melhoria do Acesso e da Qualidade da Atenção Básica. Brasília: Ministério da Saúde, 2012d. (Série B. Textos básicos de saúde).

Ministério da Saúde. Secretaria de Atenção à Saúde. Departamento de Atenção Básica. Política Nacional de Atenção Básica. Brasília: Ministério da Saúde, 2012e. (Série E. Legislação em saúde).

Presidência da República. Decreto n. 7.133, de 19 de março de 2010 - Regulamenta os critérios e procedimentos gerais a serem observados para a realização das avaliações de desempenho individual e institucional e o pagamento das gratificações de desempenho de que tratam as Leis no 9.657, de 3 de junho de 1998; no 10.484, de 3 de julho de 2002; no 10.550, de 13 de novembro de 2002; no 10.551, de 13 de novembro de 2002; no 10.682, de 28 de maio de 2003; no 10.768, de 19 de novembro de 2003; no 10.871, de 20 de maio de 2004; no 10.883, de 16 de junho de 2004; no 11.046, de 27 de dezembro de 2004; no 11.090, de 7 de janeiro de 2005; no 11.095, de 13 de janeiro de 2005; no 11.156, de 29 de julho de 2005; no 11.171, de 2 de setembro de 2005; no 11.233, de 22 de dezembro de 2005; n० 11.344, de 8 de setembro de 2006; no 11.355, de 19 de outubro de 2006; no 11.356, de 19 de outubro de 2006; no 11.357, de 19 de outubro de 2006; n 11.784, de 22 de setembro de 2008; no 11.890, de 24 de dezembro de 2008; e no 11.907, de 2 de fevereiro de 2009 . Disponível em: <http://www. planalto.gov.br/ccivil_03/Ato2007-2010/2010/Decreto/D7133. htm>. Acesso em: 03 out. 2013.

BRITO, J. C. Trabalho prescrito. Dicionário da educação profissional em saúde. FIOCRUZ. Escola Politécnica de Saúde Joaquim Venâncio. 2009. Disponível em: <http://www.epsjv.fiocruz.br/dicionario/verbetes/trapre.html>. Acesso em: 27 out. 2013.

CAMPOS, G. W. S. A política pública de saúde e a avaliação no Brasil. Prefácio. In: ONOCKO CAMPOS, R.; FURTADO, J. P. Desafios da avaliação de programas e serviços de saúde: novas tendências e questões emergentes. Campinas, SP: Editora da Unicamp, 2011.
Um método para análise e co-gestão de coletivos. 3. ed. São Paulo: Hucitec, 2007.

CARINHATO, P. H. Neoliberalismo, Reforma do Estado e políticas sociais nas últimas décadas do século XX no Brasil. Revista Aurora, ano II, n. 3, 2008. p. 37-46.

DANIELLOU, F., LAVILLE, A.; TEIGER, C. Ficção e realidade do trabaIho operário. Revista Brasileira de Saúde Ocupacional. v. 17, n. 68, 1989. p. 7-13.

FOUCAULT, M. O nascimento da biopolítica. Curso dado no College de France (1978-1979). Tradução Eduardo Brandão. São Paulo: Martins Fontes, 2008.

GUBA, E. G.; LINCOLN, Y. S. Avaliação de quarta geração. Tradução Beth Honorato. Campinas: Editora da Unicamp, 2011.

LIMA, M. E. A. Os equívocos da excelência: as novas formas de sedução na empresa. Petrópolis, RJ: Vozes, 1996.

MERHY, E. E. Em busca do tempo perdido: a micropolítica do trabalho vivo em ato, em saúde. In: MERHY, E. E.; ONOCKO, R. (orgs.) Agir em saúde: um desafio para o público. São Paulo: Hucitec, 1997. Disponível em: <http://www.uff.br/saudecoletiva/professores/merhy/capitulo-03.pdf>. Acesso em 15 set. 2013.

MÉSZÁROS, I. O desafio e o fardo do tempo histórico. Tradução Ana Cotrim e Vera Cotrim. São Paulo: Boitempo, 2011.

PINTO, H. A., SOUSA, A.; FLORÊNCIO, A. R. O Programa Nacional de Melhoria do Acesso e da Qualidade da Atenção Básica: reflexões sobre o seu desenho e processo de implantação. RECIIS: Revista Eletrônica de Comunicação, Informação e Inovação em Saúde, Rio de Janeiro: Fiocruz, v. 6, n. 2, supl., 2012. Disponível em: <http:// www.reciis.cict.fiocruz.br/index.php/reciis/article/viewArticle/624/1083>. Acesso em 14 jul. 2013.

Recebido para publicação em abril de 2013

Versão definitiva em dezembro de 2013

Suporte financeiro: CAPES

Conflito de interesse: inexistente 